\title{
Suplementação energética para vacas leiteiras pastejando azevém com alta oferta de forragem
}

\author{
Henrique Mendonça Nunes Ribeiro Filho ${ }^{1}$, Cláudio Eduard Neves Semmelmann², Maicon \\ Saulo Heydt ${ }^{1}$, André Thaler Neto ${ }^{1}$
}

\footnotetext{
1 Universidade do Estado de Santa Catarina - Centro de Ciências Agroveterinárias - Departamento de Zootecnia. Avenida Luiz de Camões, 2090 - 88520-000, Lages, SC, Brasil.

2 Programa de Pós-Graduação em Zootecnia - UFRGS
}

\begin{abstract}
RESUMO - Foi avaliado o efeito da quantidade de um suplemento energético (grão de milho) sobre o consumo de forragem e a produção de leite em vacas leiteiras pastejando azevém (Lolium multiflorum). Os tratamentos foram 2 e 4 kg de grão de milho moído/vaca.dia. Oito vacas holandesas no terço médio de lactação foram divididas em dois grupos em um delineamento de dupla reversão. A oferta de MS foi $35 \mathrm{~kg} / \mathrm{vaca}$.dia no método rotativo. O consumo individual de forragem foi estimado por meio da produção fecal e da digestibilidade da forragem selecionada. As características da forragem oferecida e da pastagem após a saída dos animais não variaram entre piquetes. A digestibilidade da MO da forragem ingerida foi 76,1 $\pm 2,77 \%$. O consumo de MO de forragem $(13,5 \pm 1,89 \mathrm{~kg} / \mathrm{dia})$, a produção de leite $(22,5 \pm 0,92 \mathrm{~kg})$ e os teores de gordura $(32,4 \pm 2,55 \mathrm{~g} / \mathrm{kg})$ e proteína do leite $(28,5 \pm 0,82 \mathrm{~g} / \mathrm{kg})$ não foram influenciados pelo nível de suplementação. Vacas leiteiras com potencial de produção de até $22,5 \mathrm{~kg} /$ dia, após o pico de produção, pastejando azevém anual manejado com alta oferta de forragem não respondem à suplementação com mais de $2,0 \mathrm{~kg}$ de grão de milho moído.
\end{abstract}

Palvras-chave: consumo de forragem, eficiência de suplementação, Lolium multiflorum, milho moído, produção de leite

\section{Energy supplementation to dairy cows grazing Italian ryegrass with high- herbage allowance}

\begin{abstract}
The effect of a energy supplement (corn grain) on the herbage intake and milk yield of lactating dairy cows grazing italian ryegrass (Lolium multiflorum) was evaluated. The treatments were 2 and $4 \mathrm{~kg}$ of ground corn/cow.day. Eight Holstein cows in the second third of their lactation were divided in two groups in switch back procedure. The expected herbage allowance was $35 \mathrm{~kg} / \mathrm{cow}$.day in rotational grazing system. Individual herbage intake was estimated from output fecal and the digestibility of the selected herbage. The characteristics of the pre-grazing herbage and post-grazing characteristics did not change between paddocks. The herbage OM digestibility was $76.1 \pm 2.77 \%$. The herbage OM intake $(13.5 \pm 1.89 \mathrm{~kg} /$ day), daily milk yield $(22.5 \pm 0.92 \mathrm{~kg} /$ day $)$, milk fat content $(32.4 \pm 2.55 \mathrm{~g} / \mathrm{kg})$ and milk protein content $(28.5 \pm 0.82 \mathrm{~g} / \mathrm{kg})$ did not differ with the supplementation levels. Dairy cows with a milk production potential of $22.5 \mathrm{~kg} / \mathrm{day}$, after milk production peak, grazing annual italian ryegrass pasture with high forage offer, did not respond to more than $2 \mathrm{~kg}$ of ground corn grain.
\end{abstract}

Key Words: efficiency of supplementation, herbage intake, Lolium multiflorum, ground corn, milk yield

\section{Introdução}

A forragem pastejada é a forma mais prática e econômica de se fornecer energia e proteína para os herbívoros ruminantes. Conseqüentemente, a rentabilidade dos sistemas de produção de leite baseados em pastagens depende do fornecimento dos nutrientes que não foram ingeridos em quantidades adequadas a partir da forragem.

Quando a pastagem possui elevado valor nutritivo (>20 \% de PB, $<50 \%$ FDN, $>75 \%$ digestibilidade da MO) e não há restrições de ordem quantitativa, a ingestão de energia constitui o primeiro fator limitante da produção de leite (Kolver, 2003). Nessas condições, o fornecimento de suplementos energéticos permite produção de leite equivalente ou superior à obtida com o uso de alguma fonte de proteína degradável no rúmen (Tesfa et al., 1995). Isso pode ser explicado pela ocorrência de importantes perdas ruminais de nitrogênio e pelo custo energético para transformação e excreção da amônia em excesso (Poppi \& McLennan, 1995).

Além do tipo de suplemento e da quantidade de alimento concentrado oferecido, o potencial de produção individual dos animais e as condições da pastagem são fatores que 
interagem e afetam diretamente a eficiência marginal de suplementação ( $\mathrm{kg}$ de leite produzido/kg de concentrado fornecido a mais), em pastagens de qualidade elevada. Conforme constatado por Peyraud \& Delaby (2001), têm ocorrido elevação na produção de leite em resposta à suplementação com concentrado, de $+0,1 \mathrm{~kg} / \mathrm{kg}$ de MS de concentrado a cada dez anos, o que se explica pela evolução do mérito genético dos animais. Quanto às interações concentrado $\times$ manejo adotado na pastagem, maiores respostas à suplementação são observadas quando a oferta de forragem impõe alguma restrição de ordem quantitativa ao consumo (Robaina et al., 1998; Delaby et al., 2001; Bargo et al., 2002). Isso ocorre porque a taxa de substituição aumenta à medida que as condições de pastejo se tornam menos limitantes (Stockdale, 2000; Peyraud \& Delaby 2001).

Verifica-se, portanto, que vários trabalhos abordando o tema da suplementação alimentar para vacas leiteiras, pastejando forragem de elevado valor alimentar, já foram realizados no exterior. No entanto, na maioria dos casos, a espécie forrageira utilizada foi o azevém perene (Lolium perene) cultivado na forma exclusiva ou em associação com trevo branco (Trifolium repens). Pouca informação tem sido gerada com as espécies forrageiras de destacada importância para o Brasil subtropical, como o azevém anual (Lolium multiflorum).

Neste trabalho, objetivou-se verificar o consumo de forragem e o nível de produção possível de ser obtido em vacas leiteiras pastejando azevém com alta oferta de forragem e suplementadas com grão de milho moído. A hipótese testada foi que vacas com potencial de produção de até $25 \mathrm{~kg}$ leite/dia em pastagem de azevém manejada com alta oferta não respondem à suplementação com mais de 2 kg de grão de milho.

\section{Material e Métodos}

O trabalho foi conduzido no Setor de Bovinocultura Leiteira da UDESC, em Lages, SC, no período de 8 de agosto a 28 de outubro/2004, em uma área de 1,2 ha situada a $27^{\circ} 47^{\prime} 4^{\prime \prime}$ de latitude Sul, 50 18' 26" de longitude Oeste e $920 \mathrm{~m}$ de altitude. O solo no local é do tipo Cambissolo Húmico Alumínico com textura franca. Antes da implantação da pastagem, foi coletada uma amostra de solo a $20 \mathrm{~cm}$ de profundidade, que apresentou os seguintes resultados: teor de argila $=470 \mathrm{~g} / \mathrm{kg}, \mathrm{pH}$ água = 5,8, índice SMP = 5,9, $\mathrm{P}=8,3 \mathrm{mg} / \mathrm{dm}^{3}, \mathrm{~K}=77 \mathrm{mg} / \mathrm{dm}^{3}$, matéria orgânica $=49 \mathrm{~g} / \mathrm{kg}$, alumínio trocável $=0,0 \mathrm{cmol}_{\mathrm{c}} / \mathrm{dm}^{3}, \mathrm{Ca}=7,5 \mathrm{cmol}_{\mathrm{C}} / \mathrm{dm}^{3} \mathrm{e}$ $\mathrm{Mg}=5,0 \mathrm{cmol}_{\mathrm{C}} / \mathrm{dm}^{3}$. Para implantação da pastagem, foram realizadas uma aplicação de calcário dolomítico e uma adubação de manutenção conforme recomendações da
Sociedade Brasileira de Ciência do Solo (2004). A semeadura do azevém foi realizada em 20 de maio de 2004, por meio de plantio direto. Trinta dias após o plantio e na sequência de cada pastejo, realizou-se uma adubação de cobertura com 50 kg de N por ha na forma de uréia.

Como tratamentos, foram avaliados dois níveis de suplementação energética (2 e 4 kg de milho moído/vaca/ dia) para vacas leiteiras em pastagem de azevém sob pastejo rotativo com oferta de $35 \mathrm{~kg}$ de MS/vaca.dia. O fornecimento do suplemento foi dividido em duas refeições após cada ordenha. Utilizaram-se oito vacas da raça Holandesa no terço médio de lactação, divididas em dois grupos, em um delineamento experimental de dupla reversão com três períodos de 12 a 15 dias ( 7 a 10 de adaptação e 5 de coleta). Os lotes foram constituídos uniformemente de acordo com a ordem de parição (primíparas ou multíparas), o estádio de lactação (130 \pm 59,7 dias), a produção de leite $(25,1 \pm 2,6$ kg/ dia) e o peso vivo (541 $\pm 50 \mathrm{~kg})$ no início do experimento.

A duração dos períodos experimentais variou de acordo com a biomassa na área, o que determinou que a ocupação dos piquetes fosse de cinco ou sete dias durante a adaptação e de cinco dias durante as avaliações. A área a ser oferecida foi delimitada por cerca elétrica móvel, de modo que o local do fio à frente foi definido de acordo com a biomassa presente e com a estimativa da taxa de crescimento. Períodos de descanso foram necessários para permitir a rebrota da forragem e a reutilização dos piquetes. Entre os períodos, os animais receberam uma dieta de transição composta de azevém, 8 kg de bagaço de cevada (22\% de MS; 28\% PB na MS) e 3 kg de grão de milho.

A biomassa foi quantificada pela relação entre a altura - medida com um disco herbométrico (Filip’s folding plate pasture meter ${ }^{\circledR}$, Jenquip company, New Zealand) - e a quantidade de MS presente no diâmetro do disco $\left(0,1 \mathrm{~m}^{2}\right)$. Foram medidos dez pontos, abrangendo desde as áreas mais baixas até as áreas mais altas da pastagem. Em cada ponto, a MS total foi cortada rente ao solo e seca em estufa com ventilação forçada a $60^{\circ} \mathrm{C}$ por 48 horas. Equações de regressão foram construídas para a estimativa da biomassa presente (kg MS/ha) de acordo com altura herbométrica (cm). A média da altura herbométrica de cada piquete foi calculada a partir de no mínimo 100 leituras.

A altura média de perfilho estendido e bainha foi medida com uma régua graduada em 200 unidades por piquete, antes do pastejo, e em 300 unidades após o pastejo. A altura média ao primeiro toque na pastagem foi medida com um bastão graduado (sward stick), também a partir de 200 medidas por piquete antes do pastejo e em 300 medidas após o pastejo. A composição morfológica foi determinada por separação manual das frações folha, colmo e material 
morto das plantas de azevém. Antes do pastejo, em todos os períodos de avaliação, foram coletadas 20 amostras da pastagem, com diâmetro de aproximadamente 10 cm, cortadas com tesoura rente ao solo. Uma subamostra foi utilizada para determinação da composição morfológica e outra subamostra foi destinada às análises químico-bromatológicas. Esta última subamostra foi cortada na altura média dos perfilhos após o pastejo. A fração superior foi seca em estufa com circulação forçada a $60^{\circ} \mathrm{C}$ por 48 horas e armazenada para determinação dos teores de MS, cinzas, PB, FDN e FDA.

O consumo individual de forragem foi medido pela quantificação da produção fecal e da digestibilidade da forragem ingerida. A produção fecal foi estimada com a utilização de um indicador externo (óxido de cromo, $\mathrm{Cr}_{2} \mathrm{O}_{3}$ ). $\mathrm{O}$ indicador foi fornecido diariamente para cada vaca em 200 g de um concentrado peletizado contendo $0,5 \%$ de $\mathrm{Cr}_{2} \mathrm{O}_{3}$ do primeiro ao penúltimo dia de cada período experimental, após cada ordenha. Amostras de fezes foram coletadas, duas vezes por dia, diretamente do reto dos animais, durante os últimos cinco dias de cada período experimental. As fezes foram secas em estufa com circulação forçada a $60^{\circ} \mathrm{C}$ por 72 horas. No final do experimento, essas amostras foram agrupadas por vaca e por período, moídas em peneira com malha de 1,0 mm e armazenadas para determinação dos teores de MS, MM, PB, FDN, FDA e cromo.

A digestibilidade da $\mathrm{MO}$ da forragem ingerida foi estimada por meio de indicadores de índice fecal, considerando o teor de PB na forragem e nas fezes e o teor de FDA nas fezes, de acordo com a equação descrita abaixo:

$$
\begin{gathered}
\mathrm{DMO}=1,035-2,478 / \mathrm{PB}_{\text {fezes }}-0,00027 \mathrm{FDA}_{\text {fezes }}{ }^{-} \\
0,0571 \mathrm{~PB}_{\text {forragem }} / \mathrm{PB}_{\text {fezes }} \\
\left(\mathrm{n}=31, \mathrm{R}^{2}=0,92, \text { erro-padrão }=0,0094\right) .
\end{gathered}
$$

Esta equação foi obtida a partir dos resultados de 31 experimentos in vivo, conduzidos na fazenda experimental do Institut National de la Recherche Agronomique (INRA), próximo a Rennes (Bretanha, França). Nestes ensaios, utilizaram-se 3 a 4 vacas alimentadas em estábulos com forragem fresca de azevém perene, capim-dos-pomares ou trevo-branco (Peyraud et al., não publicado).

A produção de leite individual foi medida diariamente em cada ordenha. Amostras para determinação dos teores de gordura e proteína do leite foram coletadas nas ordenhas do segundo e quarto dia dos períodos de avaliação. Uma vez por semana os animais foram pesados. O balanço energético foi calculado pela diferença entre o consumo de energia líquida (consumo de forragem $\times$ conteúdo de energia líquida da forragem) e as exigências em energia líquida para mantença e produção de leite, de acordo com o sistema de unidade alimentar desenvolvido pelo Institut National de la Recherche Agronomique (1989). O conteúdo de energia líquida de lactação da forragem foi calculado considerando eficiência de utilização da energia metabolizável de 0,63 (INRA, 1989). A energia metabolizável da forragem ingerida foi estimada a partir de sua DMO, conforme proposto pela AFRC (1993).

A determinação da composição químico-bromatológica das amostras da forragem e das fezes foi realizada nas amostras secas ao ar e moídas em partículas de 1,0 mm. A MS total foi determinada por secagem a $105^{\circ} \mathrm{C}$ até peso constante. O teor de cinzas foi quantificado por incineração das amostras em um forno mufla a $550^{\circ} \mathrm{C}$ por 4 horas. O teor de $\mathrm{PB}(\mathrm{N} \times 6,25)$ foi dosado por meio de um procedimento semimicro Kjeldahl, conforme descrito por Silva \& Queiroz (2002). A análise das frações FDN e FDA na forragem e nas fezes foi realizada incluindo as cinzas residuais sem utilização de $\alpha$-amilase (Mertens, 2002). A porcentagem de cromo foi obtida por espectrofotometria de absorção atômica (Williams et al., 1962).

Os dados foram submetidos à análise de variância utilizando-se um modelo linear generalizado. As variáveis dos animais foram analisadas considerando os fatores vaca, período e nível de suplementação $(n=24)$. As variáveis da pastagem foram analisadas considerando os fatores período e nível de suplementação $(n=6)$.

\section{Resultados e Discussão}

As características da forragem oferecida entre os piquetes utilizados não foram influenciadas $(\mathrm{P}>0,05)$ pelos níveis de suplementação (Tabela 1). A biomassa pré-pastejo foi em média $3067 \mathrm{~kg} / \mathrm{ha}$. As alturas médias obtidas pelo disco herbométrico, bastão graduado e de perfilho estendido foram 147, 293 e $440 \mathrm{~mm}$, respectivamente. As alturas medidas pelo disco herbométrico corresponderam a $50 \%$ da altura com o bastão graduado e 30 a $35 \%$ da altura de perfilho estendido. A composição morfológica da MS apresentou média de 40,78\% de lâmina foliar, 51,43\% de bainha, $5,42 \%$ de material morto e 2,37\% de outras espécies. Os teores de PB, FDN e FDA foram 19,05; 58,18; e 28,40\%, respectivamente.

Os valores médios da composição química da forragem foram próximos da amplitude observada em pastagens de elevada qualidade utilizadas em regiões com tradição na produção de leite em pastagem, como o Nordeste dos Estados Unidos (Kolver \& Muller, 1998), a Austrália (Stockdale, 1999), a Nova Zelândia (Kolver, 2003), a Irlanda 
Tabela 1 - Biomassa, altura, composição morfológica e composição química da forragem pré-pastejo em azevém anual pastejado por vacas leiteiras sob suplementação energética

Table 1 - Herbage mass, sward height, morphological composition and chemical composition on italian ryegrass swards grazed by dairy cows receiving energetic supplementation

\begin{tabular}{lcccc}
\hline Item & $\begin{array}{c}\text { Grão de milho }(\mathrm{kg} / \mathrm{d}) \\
\text { Corn grain }\end{array}$ & $\begin{array}{c}\text { DPR } \\
\text { RSD }\end{array}$ & $\begin{array}{c}\text { Valor de P } \\
\text { P-value }\end{array}$ \\
\cline { 2 - 3 } & 2 & 4 & & \\
\hline $\begin{array}{l}\text { Biomassa }(\mathrm{kg} \mathrm{MS} / \mathrm{ha}) \\
\text { Herbage mass }(\mathrm{kg} \mathrm{DM} / \mathrm{ha})\end{array}$ & 3.074 & 3.060 & 494,1 & $\mathrm{~ns}$ \\
\hline
\end{tabular}

Altura pré-pastejo ( $\mathrm{mm})$

Pre-grazing sward height $(\mathrm{mm})$

\begin{tabular}{|c|c|c|c|c|}
\hline $\begin{array}{l}\text { Disco herbométrico } \\
\text { Rising plate meter }\end{array}$ & 151 & 142 & 52,8 & ns \\
\hline $\begin{array}{l}\text { Bastão graduado } \\
\text { Sward stick }\end{array}$ & 294 & 291 & 66,5 & ns \\
\hline $\begin{array}{l}\text { Perfilho estendido } \\
\text { Extended tiller }\end{array}$ & 424 & 456 & 131,9 & ns \\
\hline $\begin{array}{l}\text { Bainha estendida } \\
\text { Extended sheath }\end{array}$ & 216 & 224 & 122,3 & ns \\
\hline
\end{tabular}

Composição morfológica (\% MS)

Morphological composition (\% DM)

\begin{tabular}{|c|c|c|c|c|}
\hline $\begin{array}{l}\text { Lâmina foliar } \\
\text { Leaf blade }\end{array}$ & 42,62 & 38,94 & 4,21 & ns \\
\hline $\begin{array}{l}\text { Bainha e colmo } \\
\text { Sheath and stem }\end{array}$ & 49,37 & 53,49 & 3,03 & ns \\
\hline $\begin{array}{l}\text { Material morto } \\
\text { Dead material }\end{array}$ & 6,60 & 4,25 & 1,18 & ns \\
\hline $\begin{array}{l}\text { Outras espécies } \\
\text { Other species }\end{array}$ & 1,41 & 3,32 & 1,17 & ns \\
\hline
\end{tabular}

Composição química (\% MS)

Chemical composition (\% DM)

\begin{tabular}{lrrrr}
\hline MS (\% forragem verde) & 23,15 & 24,08 & 1,05 & ns \\
$\begin{array}{l}\text { M (\% fresh herbage) } \\
\text { Matéria mineral }\end{array}$ & 7,31 & 7,22 & 0,40 & ns \\
$\begin{array}{l}\text { Ash } \\
\text { PB }\end{array}$ & 19,56 & 18,54 & 0,82 & ns \\
CP & 58,57 & 57,80 & 1,51 & ns \\
FDN & 27,43 & 29,38 & 1,10 & ns \\
NDF & & & & \\
FDA & & & \\
ADFe & & & \\
\hline
\end{tabular}

$\mathrm{DPR}=$ desvio-padrão residual $(R S D=$ residual standard deviation).

(Dillon et al., 2002) e o Nordeste da França (Delaby et al., 2001). Nesses locais, as pastagens utilizadas são constituídas basicamente de azevém perene e apresentam valores de PB, FDN e DMO que variam, respectivamente, de 16,1 a 25\%, de 40 a $55 \%$ e de 75 a $82 \%$. A elevada qualidade da forragem observada neste trabalho, do mesmo modo que observado por outros autores (Dixon \& Stockdale,1999; Stockdale, 1999), pode contribuir para explicar a ausência de um efeito associativo positivo com a suplementação utilizada.

A área oferecida por vaca foi de aproximadamente $100 \mathrm{~m}^{2} /$ dia em ambas as ofertas de forragem (Tabela 2). A oferta de MS total, MS verde e MS de lâminas verdes por vaca foram 36,2; 33,25 e 14,2 kg/dia, respectivamente. As alturas médias pós-pastejo obtidas pelo disco herbométrico, pelo bastão graduado e de perfilho estendido foram 104, 239 e $251 \mathrm{~mm}$. A proporção de desaparecimento da altura oferecida foi, em média, de 0,30 quando medida pelo disco e 0,18 quando medida pelo bastão.

A oferta diária de forragem observada foi suficiente para não impor qualquer limitação de ordem não nutricional ao consumo. A existência de uma relação curvilinear entre a oferta de forragem e o consumo é bastante conhecida e níveis de oferta superiores a $35 \mathrm{~kg}$ MS seriam suficientes para evitar restrições de ordem quantitativa à ingestão (Peyraud et al., 1996; Stockdale, 2000; Delagarde et al., 2001a; Bargo et al., 2003). A inexistência de alguma restrição de ordem quantitativa pode ser comprovada, ainda, pela relação altura residual/altura inicial, medida com o disco herbométrico. Segundo Delagarde et al. (2001b, 2006), no método de pastejo rotativo ou em faixas diárias, o consumo de forragem é limitado quando a porcentagem de desaparecimento da altura inicial, medida com o disco herbométrico, ultrapassa $40 \%$. Além disso, aproximadamente $40 \%$ da altura inicial dos perfilhos e somente $16 \%$ das bainhas foram desfolhadas. A pequena proporção de bainhas no estrato contribuiu para a elevação da qualidade da forragem ingerida.

O consumo de forragem e a digestibilidade da matéria orgânica (DMO) não foram afetados pelo nível de suplementação com grão de milho (Tabela 3 ). O consumo individual de MS esteve acima de 15,0 kg/dia, enquanto a DMO da forragem foi superior a 0,75 . Os consumos de $\mathrm{MO}$ digestível da forragem e de MO digestível total também não diferiram $(\mathrm{P}>0,05)$ entre os níveis de suplementação. $\mathrm{O}$ consumo médio de MO digestível foi $12 \mathrm{~kg} / \mathrm{dia}$, o que possibilitou balanço energético positivo de aproximadamente 14,5 MJ de energia líquida de lactação por dia.

A ausência de variação no consumo de forragem com o aumento da quantidade de grão de milho de 2 para $4 \mathrm{~kg} /$ dia é pouco comum, uma vez que, na maioria dos casos, ocorre aumento da substituição quando as condições da pastagem não são limitantes (Kibon \& Holmes, 1987; Robaina et al., 1998; Bargo et al., 2002). Contudo, inexistência de substituição em situação de alta oferta foi relatada por Stakelum (1986) em massa de forragem pré-pastejo por volta de $2.900 \mathrm{~kg} / \mathrm{ha}$, situação semelhante à encontrada neste trabalho. Quando a massa de forragem inicial aumentou para $3.500 \mathrm{~kg}$ de MS/ha, esse mesmo autor observou redução no consumo de MO de forragem de $2 \mathrm{~kg} / \mathrm{vaca} / \mathrm{dia}$. O consumo de MO total não variou entre tratamentos, provavelmente porque as vacas que receberam grão de milho 
Tabela 2 - Manejo adotado, oferta de forragem e altura póspastejo em uma área de azevém anual pastejado por vacas leiteiras sob suplementação energética

Table 2 - Grazing management, herbage allowance and post-grazing sward height on Italian ryegrass swards grazed by dairy cows receiving energy supplementation

\begin{tabular}{lcccc}
\hline Item & $\begin{array}{c}\text { Grão de milho (kg/d) } \\
\text { Corn grain }\end{array}$ & $\begin{array}{c}\text { DPR } \\
\text { RSD }\end{array}$ & $\begin{array}{c}\text { Valor de P } \\
\text { P-value }\end{array}$ \\
\cline { 2 - 3 } & 2 & 4 & & \\
\hline $\begin{array}{l}\text { Área oferecida } \\
\left(\mathrm{m}^{2} / \text { vaca.d) }\right.\end{array}$ & 99,2 & 103 & 6,38 & $\mathrm{~ns}$ \\
\begin{tabular}{l} 
Offered area \\
\hline
\end{tabular} & & & & \\
\hline
\end{tabular}

Oferta de forragem (kg MS/vaca.d)

Herbage allowance ( $\mathrm{kg}$ DM/cow.d)

\begin{tabular}{|c|c|c|c|c|}
\hline MS total & 35,3 & 37,1 & 2,70 & ns \\
\hline Total DM & & & & \\
\hline $\begin{array}{l}\text { MS verde } \\
\text { Live material }\end{array}$ & 32,3 & 34,2 & 2,04 & ns \\
\hline $\begin{array}{l}\text { MS de lâminas foliares } \\
\text { Leaf blade DM }\end{array}$ & 13,8 & 14,6 & 5,70 & ns \\
\hline
\end{tabular}

Altura pós-pastejo (mm)

Post-grazing sward height ( $\mathrm{mm}$ )

\begin{tabular}{|c|c|c|c|c|}
\hline $\begin{array}{l}\text { Disco herbométrico } \\
\text { Rising plate meter }\end{array}$ & 104 & 103 & 42,7 & ns \\
\hline $\begin{array}{l}\text { Bastão graduado } \\
\text { Sward stick }\end{array}$ & 224 & 253 & 114,6 & ns \\
\hline $\begin{array}{l}\text { Perfilho estendido } \\
\text { Extended tiller }\end{array}$ & 264 & 238 & 98,8 & ns \\
\hline $\begin{array}{l}\text { Bainha estendida } \\
\text { Extended sheath }\end{array}$ & 199 & 170 & 95,4 & ns \\
\hline
\end{tabular}

DPR $=$ desvio-padrão residual $(R S D=$ residual standard deviation $)$.

(4 kg/dia) deixaram quantidade de sobras um pouco maior que a deixada pelas vacas que receberam $2 \mathrm{~kg}$ de suplemento. A diferença entre o consumo de MO total e o consumo de $\mathrm{MO}$ de forragem foi de $1,5 \mathrm{~kg}$ para os animais recebendo $2 \mathrm{~kg}$ de grão de milho e de 2,6 kg/MO para os animais que receberam $4 \mathrm{~kg}$ de milho (Tabela 3 ).

A produção de leite e os teores de gordura e de proteína no leite não variaram $(\mathrm{P}>0,05)$ quando o nível de suplementação com grão de milho aumentou de 2 para 4 kg/ vaca/dia (Tabela 4). A produção de leite individual foi superior a $22,0 \mathrm{~kg} /$ dia e os teores de gordura e proteína foram 32,4 e 28,5 g/kg, respectivamente. O balanço energético foi, em média, +14,4 MJ de energia líquida de lactação $\left(E L_{L}\right) /$ dia. O peso vivo médio dos animais ao longo do experimento foi 568 kg e não diferiu significativamente entre as ofertas de forragem.

A inexistência de resposta na produção de leite provavelmente ocorreu porque a energia obtida da pastagem mais a suplementação com $2 \mathrm{~kg}$ de grão de milho foi suficiente para atender às exigências nutricionais para o máximo potencial de produção individual. Considerando diminuição teórica da produção de leite de $2 \%$ por semana de
Tabela 3 - Produção fecal, digestibilidade da forragem ingerida, consumo e balanço energético de vacas leiteiras em pastagem de azevém anual com suplmentação energética

Table 3 - $\quad$ Fecal output, herbage digestibility, herbage intake and energy balance in dairy cows grazing annual Italian ryegrass with energy supplementation

\begin{tabular}{|c|c|c|c|c|}
\hline \multirow[t]{2}{*}{ Item } & \multicolumn{2}{|c|}{$\begin{array}{c}\text { Grão de milho }(\mathrm{kg} / \mathrm{d}) \\
\text { Corn grain }\end{array}$} & \multirow[t]{2}{*}{$\begin{array}{l}\text { DPR } \\
R S D\end{array}$} & \multirow[t]{2}{*}{$\begin{array}{c}\text { Valor de } \mathrm{P} \\
P \text {-value }\end{array}$} \\
\hline & 2 & 4 & & \\
\hline $\begin{array}{l}\text { Produção fecal } \\
\text { (kg MO/dia) } \\
\text { Faecal output (kg OM/day) } \\
\text { Digestibilidade } \\
\text { MO forragem }{ }^{1} \\
\text { Herbage OM digestibility }\end{array}$ & 0,762 & 0,759 & 0,41 & ns \\
\hline \multicolumn{5}{|l|}{$\begin{array}{l}\text { Consumo }(\mathrm{kg} / \mathrm{d}) \\
\text { Intake }\end{array}$} \\
\hline $\begin{array}{l}\text { MS forragem } \\
\text { Herbage DM }\end{array}$ & 14,6 & 14,4 & 1,58 & ns \\
\hline $\begin{array}{l}\text { MO forragem } \\
\text { Herbage OM }\end{array}$ & 13,5 & 13,3 & 1,47 & ns \\
\hline $\begin{array}{l}\text { MO digestível } \\
\text { forragem } \\
\text { Herbage DOM }\end{array}$ & 10,3 & 10,1 & 1,12 & ns \\
\hline $\begin{array}{l}\text { MO total } \\
\text { Total OM }\end{array}$ & 15,0 & 15,9 & 1,70 & ns \\
\hline $\begin{array}{l}\text { MO digestível total } \\
\text { Total DOM }\end{array}$ & 11,6 & 12,4 & 1,31 & ns \\
\hline $\begin{array}{l}\text { Balanço energético } \\
\text { (MJ EL lactação/dia) } \\
\text { Energy balance (MJ NE/day }\end{array}$ & 13,1 & 15,7 & 13,0 & ns \\
\hline
\end{tabular}

DPR = desvio-padrão residual $(R S D=$ residual standard deviation $)$.

${ }^{1}$ Estimada a partir de indicadores de índice fecal (Estimated from faecal index).

2 Calculado a partir de equações INRA (1989) e ARFC (1993) (Calculated from INRA, 1989) and ARFC, 1993).

lactação e considerando que a produção média inicial dos animais utilizados neste trabalho foi $25,1 \mathrm{~kg} / \mathrm{dia}$, a produção de leite esperada ao final de seis semanas (metade do experimento) seria 22,2 kg de leite, ou seja, muito próxima da média observada. Baixa eficiência de suplementação para vacas leiteiras pastejando forragem de qualidade, em situação de alta oferta, foi observada por diversos autores (Kibon \& Holmes, 1987; Robaina et al., 1998; Delaby et al., 2001; Bargo et al., 2002).

Provavelmente, se o mesmo experimento fosse conduzido com vacas de maior potencial de produção, seria observado um aumento na eficiência marginal de suplementação. Dillon et al. (2002), trabalhando com vacas em início de lactação, observaram que a resposta à suplementação com concentrado está intimamente associada ao nível de produção dos animais. Esses autores sugeriram ainda que as quantidades adicionais de nutrientes seriam disponibilizadas para diminuir a mobilização de reservas corporais. Elevações no ganho de peso foram observadas por Kibon \& Holmes (1987) quando vacas 
Tabela 4 - Produção e composição do leite e peso vivo de vacas leiteiras em pastagem de azevém anual (Lolium multiflorum) com suplementação energetica

Table 4 - Milk and milk composition and live weight in dairy cows grazing annual italian ryegrass with energy supplementation

\begin{tabular}{|c|c|c|c|c|}
\hline \multirow[t]{2}{*}{ Item } & \multicolumn{2}{|c|}{$\begin{array}{c}\text { Grão de milho }(\mathrm{kg} / \mathrm{d}) \\
\text { Corn grain }\end{array}$} & \multirow[t]{2}{*}{$\begin{array}{l}\text { DPR } \\
R S D\end{array}$} & \multirow[t]{2}{*}{$\begin{array}{l}\text { Valor de } \mathrm{P} \\
P \text {-value }\end{array}$} \\
\hline & 2 & 4 & & \\
\hline $\begin{array}{l}\text { Produção de leite } \\
(\mathrm{kg} / \mathrm{d}) \\
\text { Milk yield }\end{array}$ & 22,3 & 22,6 & 0,92 & ns \\
\hline $\begin{array}{l}\text { Produção de gordura } \\
\text { (g/d) } \\
\text { Milk fat yield }\end{array}$ & 726 & 739 & 57,6 & ns \\
\hline $\begin{array}{l}\text { Produção de proteína } \\
\text { (g/d) }\end{array}$ & 637 & 653 & 33,8 & ns \\
\hline $\begin{array}{l}\text { Milk protein yield } \\
\text { Produção de leite } \\
4 \%(\mathrm{~kg} / \mathrm{d})\end{array}$ & 19,7 & 20,1 & 0,92 & ns \\
\hline $\begin{array}{l}\text { Fat-corrected milk yield } \\
\text { Teor de gordura }(\mathrm{g} / \mathrm{kg}) \\
\text { Milk fat content }\end{array}$ & 32,1 & 32,6 & 2,55 & ns \\
\hline $\begin{array}{l}\text { Teor de proteína }(\mathrm{g} / \mathrm{kg}) \\
\text { Milk protein content }\end{array}$ & 28,2 & 28,8 & 0,82 & ns \\
\hline $\begin{array}{l}\text { Peso vivo (kg) } \\
\text { Live weight }\end{array}$ & 570 & 566 & 8,1 & ns \\
\hline
\end{tabular}

DPR = desvio-padrão residual $(R S D=$ residual standard deviation $)$.

\section{Conclusões}

Em pastagem de azevém manejada com alta oferta, vacas leiteiras após o pico de lactação com produção de leite esperada de até $22,5 \mathrm{~kg} /$ dia não respondem à suplementação com mais de 2,0 kg de milho moído. Trabalhos devem ser conduzidos para avaliar vacas leiteiras com alto potencial de produção em pastagem de azevém, com e sem suplementação com concentrado.

\section{Agradecimento}

Aos acadêmicos Francielli Cordeiro Zimermann e Reges Luís Ferreira Conteçotto, pelo suporte nas determinações e medidas das pastagens. Ao projeto gado leiteiro do CAV/UDESC, especialmente ao técnico João Pedro de Paula, pelo auxílio nas atividades de manejo do rebanho leiteiro. Ao Programa de bolsistas de iniciação científica PROBIC/UDESC, ao Departamento de Zootecnia do CAV/ UDESC e ao Programa de Pós-Graduação em Zootecnia da UFRGS, pelo suporte e auxílio deste trabalho de pesquisa.

\section{Literatura Citada}

leiteiras tiveram acesso a pastagens com maior altura, manejada em lotação contínua. Mais recentemente Horan et al. (2005) constataram que a resposta à suplementação com concentrado depende, em grande parte, do mérito genético dos animais. Verifica-se, portanto, que, em concordância com os resultados observados neste experimento, a resposta ao nível de suplementação com concentrado é pouco associada à quantidade de suplemento fornecido per si, mas depende, sobretudo, da relação entre a quantidade de energia exigida e a quantidade de energia ingerida da forragem. Considerando que o balanço energético no menor nível de suplementação foi + 13,1 MJ de energia líquida de lactação por dia, pode-se afirmar que a energia obtida da forragem mais o concentrado atenderam com sobra às exigências para o potencial de produção dos animais utilizados neste estudo.

A ausência na alteração dos teores de gordura e proteína do leite está de acordo com o esperado, uma vez que diminuições no teor de gordura são normalmente observadas quando a quantidade de concentrado fornecido por vaca é superior a 4 kg/dia (Peyraud et al., 2001). Com relação à proteína, alterações negativas são, via de regra, acompanhadas de diminuições na produção de leite, advindas de um déficit energético que limita, também, a síntese protéica na glândula mamária (Coulon \& Rémond, 1991), o que não aconteceu neste trabalho.
AGRICULTURAL AND FOOD RESEARCH COUNCIL - AFRC. Energy and protein requirements of ruminants. Wallinford: CAB International, 1993. 159p.

BARGO, F.; MULLER, L.D.; DELAHOY, J.E. et al. Milk response to concentrate supplementation of high producing dairy cows v.85, n.7, p.1777-1792, 2002.

BARGO, F.; MULLER, L.D.; KOLVER, E.S. et al. Invited review: production and digestion of supplemented dairy cows on pasture. Journal of Dairy Science, v.86, p.1-42, 2003.

COULON, J.B.; RÉMOND, B. Variations in milk output and milk protein content in response to the level of energy supply to the dairy cow: a review. Livestock Production Science, v.29, p.31-47, 1991.

DELABY, L.; PEYRAUD, J.L.; DELAGARDE, R. Effect of the level of concentrate supplementation, herbage allowance and milk yield at turn-out on the performance of dairy cows in mid lactation at grazing. Animal Science, v.73, p.171-181, 2001.

DELAGARDE, R.; PEYRAUD, J.L.; PARGA, J. et al. Caractéristiques de la prairie avant et après un pâturage: quels indicateurs de l'ingestion chez la vache laitière? Rencontre Recherche Ruminants, v.8, p.209-212, 2001a.

DELAGARDE, R.; PRACHE, S.; D'HOUR, P.D. et al. Ingestion de l'herbe par les ruminats au pâturage. Fourrages, v.166, p.189212, 2001b.

DELAGARDE, R.; DELABY, L.; FAVERDIN, P. Le calcul de ration pour vaches laitiéres au pâturage. Rencontre Recherche Ruminants, v.13, 2006.

DILLON, P.; CROSSE, S.; O'BRIEN, B. et al. The effect of forage type and level of concentrate supplementation on the performance of spring-calving dairy cows in early lactation. Grass and Forage Science, v.57, p.1-12, 2002.

DIXON, R.M.; STOCKDALE, C.R. Associative effects between forages and grains: consequences for feed utilization. Australian Journal of Agriculture Research, v.90, p.757773, 1999. grazing at two pasture allowance. Journal of Dairy Science, 
HORAN, B.; DILLON, P.; FAVERDIN, P. et al. The interation of strain of holtein-friesian cows and pasture-based feed systems on milk yield, body weight, and body condition score. Journal of Dairy Science, v.88, p.1231-1243, 2005.

INSTITUT NATIONAL DE LA RECHERCHE AGRONOMIQUE INRA. Ruminant nutrition: recommended allowances and feed tables. London: John Libbey Eurotext, 1989. 389p.

KIBON, A.; HOLMES, C. The effect of height of pasture and concentrate composition on dairy cows grazed on continuously stocked pastures. Journal of Agriculture Science, v.109, p.293-301, 1987.

KOLVER, E.S.; MULLER, L.D. Performance and nutrient intake of high producing holstein cows consuminig pasture or a total ration. Journal of Dairy Science, v.81, p.1403-1411, 1998.

KOLVER, E.S. Nutritional limitations to increased production on pasture-based systems. Proceedings of the Nutrition Society, v.62, p.291-300, 2003

MERTENS, D.R. Gravimetric determination of amylase-treated neutral detergent fibre in feeds with refluxing beakers or crucibles: collaborative study. Journal of Association Official Chemistry International, v.85, p.1217-1240, 2002.

PEYRAUD, J.L.; COMERON, E.A.; WADE, M.H. et al. The effect of daily herbage allowance, herbage mass and animal factors upon herbage intake by grazing dairy cows. Annales Zootechnie, v.45, p.201-217, 1996.

PEYRAUD, J.L.; DELABY, L. Ideal concentrate feeds for grazing dairy cows - responses to supplementation in interaction with grazing management and grass quality. In: RECENTS ADVANCES IN ANIMAL NUTRITION - UNIVERSITY OF NOTHINGHAM FEED CONFERENCE, 35., 2001, Nothingham. Proceedings... Nothingham: [s.n.], 2001. p.203-220.

POPPI, D. P.; MCLENNAN, S.R. Protein and energy utilization by ruminants at pasture. Journal of Animal Science, v.73, p.278290, 1995.
ROBAINA, A.C.; GRAINER, C.; MOATE, P. et al. Responses to grain feeding by grazing dairy cows. Australian Journal of Experimental Agriculture, v.38, p.541-549, 1998.

SILVA, D.J.; QUEIROZ, A.C. Análise de alimentos: métodos químicos e biológicos. 3.ed. Viçosa, MG: Universidade Federal de Viçosa, 2002. 235p.

SOCIEDADE BRASILEIRA DE CIÊNCIA DO SOLO. Comissão de química e fertilidade do Solo. Manual de adubação e calagem para os Estados do Rio Grande do Sul e Santa Catarina. 10.ed. Porto Alegre, 2004. 400p.

STAKELUM, G. Herbage intake of grazing dairy cows. 2. Effect of herbage allowance, herbage mass and concentrate feeding on the intake of cows grazing primary spring grass. Irish Journal of Experimental Research, v.25, p.41-51, 1986.

STOCKDALE, C.R. The nutritive characteristics of herbage consumed by grazing dairy cows affect milk responses obtained from concentrate supplementation. Australian Journal of Experimental Agriculture, v.39, p.379-387, 1999.

STOCKDALE, C.R. Levels of pasture substitution when concentrate are fed to grazing dairy cows in nothern Victoria. Australian Journal of Experimental Agriculture, v.40, p.913-921, 2000.

TESFA, A.T.; VIRKAJÄRVI, P.; TUORI, M. et al. Effects of supplementary concentrate composition on milk yield, milk composition and pasture utilization of rotationally grazed dairy cows. Animal Feed Science and Technology, v.56, p.13154, 1995.

WILLIAMS, C.H.; DAVID, D.J.; IISMA, O. The determination of chromic oxide in feces samples by atomic absortion spectrophotometry. Journal of Agriculture Science, v.59, p.381-385, 1962. 